\title{
SUBJETIVIDAD INFANTIL, \\ LO POLÍTICO \\ Y LA PARTICIPACIÓN
}

En el presente texto se exponela importancia de reconocer en la vida cotidiana el ámbito natural en el que se aprende a ser buen ciudadano, y el compromiso de los adultos frente a la educación de los niños en asuntos relacionados con lo político y la participación. Se muestra cómo las acciones humanas son un acto deliberativo que implica al otro, por lo que se requiere educar al niño parael respeto, el cuidado yl a alteridad. Ponerse en el lugar del otro es, entonces, un acto responsable al que le deviene un nosotros, acto fundante de las prácticas colectivas. Asimismo, se muestra la importancia de dar titularidad a los derechos de los niños pero también a su experiencia, desnaturalizando la imagen despolitizada del niño ${ }^{1}$ para considerarlos productores de cultura parte de la sociedad que participan de sus procesos con sus opiniones y acciones. De ahí, que escuchar sus voces de manera genuina podría favorecer el nacimiento de una nueva humanidad.

Palabras clave: subjetividad infantil, político, participación.

1 Este término se utiliza de modo genérico (en él aplica tanto niño como niña). 
To recognize the relevance of everyday life, the natural environment in which we learn to be good citizens and the commitment of adults towards the education of children related to politics and participation is exposed in this paper. This article shows how human actions are a deliberative act involving others for what is required to educate the child into respect, care and otherness. Putting ourselves in the other's place is therefore a responsible act to which turns out to be a 'we' that becomes a founding act of collective practices. It is presented the importance of giving ownership to the rights of children but also to their experience, distorting the image of the child depoliticized culture producers to consider them part of a society involved in its processes with their opinions and actions; hence their voices can be heard genuinely to favor the birth of a new humanity.

Keywords: Children subjectivity, politics and participation

"La política es también la manera como los seres humanos organizan su vida en la tierra, sus esfuerzos por construir un mundo donde podrán ser libres e iguales, donde no volverán a mirarse como enemigos, sino como hermanos"

Denis Langlois

La infancia cobra relevancia al ser una etapa sensible, donde la interacción con los demás y con su propia cultura permite a los niños formarse como actores sociales auténticos, ávidos de ser interpretados y contemplados como sujetos activos 
dentro de la sociedad; ponderando en ellos un papel protagónico como fuente generadora de cambios trascendentales, capaces de impactar realidades y contribuir a los progresos sociales.

Esta mirada de la infancia aproxima a la humanidad al encuentro y al reconocimiento del otro como un nosotros, estructura intencional que permite concebir el cuidado de sí mismo y el de los demás como un acto de reciprocidad, que fortalece los lazos de solidaridad necesarios para el avance y el progreso de la sociedad.

Es por eso que la perspectiva de escuchar atentamente la voz de los niños se hace inaplazable, de lo que se puede establecer la participación de ellos como la ruta más acertada en la búsqueda de su visibilización; pues son los niños quienes demuestran ser capaces -desde su experiencia- de manifestar, de proponer y de ejecutar intervenciones trascendentales que logran transformar sus propios entornos, legitimando su protagonismo como seres sociales y merecedores de reconocimiento en los diferentes escenarios.

Tradicionalmente, la infancia se ha considerado como un grupo social incapaz de hacer discernimientos, por lo que se naturaliza un ocultamiento a la vida pública del niño, quitándole la posibilidad de actuar. El niño se ha despolitizado, todo esto, producto de la idea de niñez como una etapa de preparación para la vida adulta, y esta última, como cúspide en lo referido a la ciudadanía; es decir, solo se es ciudadano si se es adulto. Alvarado, S (2014) escribe al respecto: "El desarrollo humano de los niños, niñas y jóvenes ha estado atrapados en la naturalización de sus condiciones y en la despolitización de su ser en el mundo" (p.22). Cuando en realidad se es ciudadano desde que se nace, desde que la vida nos abraza y desde que se llega al mundo en el que cada sujeto es insertado inserta, es decir, donde inicia la vida en un escenario común, en el cual surge lo político y la relación con los otros: allí podemos ver dos perspectivas: una, como un proceso que se construye en la relación entre sujetos, en el reconocimiento de sí mismo y de los otros; y dos, como una capacidad humana que permite establecer acuerdos desde la diversidad y la pluralidad.

Educ. Foco, Juiz de Fora, v. $21, n .2$, p.333-344, maio/ago. 2016 
Lo político es tan antiguo como el género humano, su ejercicio se remonta al encuentro entre sujetos que se reconocen como diferentes en sus individualidades y particularidades, que requieren ponerse de acuerdo sobre acuerdos y desacuerdos. Lo político surge cuando un sujeto se encuentra con otro, reconociendo que ese otro noeséllo complementa, permitiéndole saber que él es el otro de otro, y que en su complemento forman el nosotros. Como lo describe Luna (2014):

El sujeto político es primero un sujeto cuerpo que aparece y al que las cosas le parecen; es decir, es un sujeto que aparece y reconoce a los otros que aparece, y ese reconocer vuelto parecer se origina en experiencias primarias de gusto o desagrado, de aceptación o rechazo (LUNA, 2014, pp- 133-134).

De este modo, el reconocimiento del otro, la mirada de lo diferente y la necesidad de llegar a acuerdos para convivir constituyen lo político, y se genera así una vivencia de una común unidad, sana, respetuosa y genuina. Aludir al bien común sugiere que en la relación de lo político, la alteridad y el diálogo, se dispongan decididamente al servicio de la vida, especialmente de la vida humana.

En la esfera de lo político, que es el bien común, es necesario un por lo que lo político tiene un interlocutor y es el bien común, al que como misión le deviene favorecer espacios para una ciudadanía de las distintas infancias; como mensaje de esperanza; en donde sea posible el respeto a los niños por medio de una alianza con ellos-quienes también son aptos para la construcción de ciudadanía- ya que son hábiles y con capacidades para asuntos como la negociación, la aceptación de la diferencia, el diálogo intersubjetivo y la comprensión de lo diferente y el encuentro con otros.

Es en ese diálogo intersubjetivo donde cobra valor la diferencia, y es en la escucha seria y atenta de la voz de los niños donde se abren escenarios reales de participación y de 
reconocimiento de la riqueza infantil, desde la valoración de la palabra, del conocimiento y del sentimiento que posee cada niño.

Despolitizar al niño implica asumir que la participación es un asunto de otros, que no toca al sujeto del común, frente a la idea de que lo político no es para los niños, sino que se ve como un asunto que ha de tratarse cuando se tenga edad para razonar. Esta concepción es el punto de partida para la generación de propuestas que involucren a los niños, de tal manera que hagan parte de este mundo de lo político, desde una construcción que pone como centro al ser humano.

Se requiere entonces una sociedad en la que una vida diferente sea posible y donde lo político vuelva a ser esencial para la vida; se necesita ir al encuentro de una renovada humanidad, para cumplir con la condición indispensable del respeto por el otro, que en palabras de Hannah Arendt es "la irreductible pluralidad queda expresada en el hecho de que somos alguien y no algo" (ARENDT, 1997 p.22), para que, de nuevo en lo político, emerja una nueva conciencia en donde el ser humano pueda estar en comunidad, unos y otros en la diversidad, para así retornar a la misión y fin de lo político, que es el de asegurar la vida en el sentido más amplio. Así, lo político existirá como cualidad que se construye y surge en toda interrelación humana y busca el beneficio común.

\section{EL ENCUENTRO CON EL OTRO: UN ESPACIO PARA LO POLÍTICO}

"La acogida del otro significa... confianza, acompañamiento..., pero también aceptar ser enseñado por ese 'otro' que irrumpe en nuestra vida" Ortega, R

Educar a los más pequeños en asuntos de la participación, lo individual y lo colectivo, conduce a considerar los planteamientos de Lévinas (1993), quien nos muestra la

Educ. Foco,

Juiz de Fora, v. 21, n.2, p.333-344, 
importancia de educar en los sujetos una conciencia ética exigente, que nos habla de imperativos de responsabilidad total del hombre para con el "otro". Una conciencia de la responsabilidad, que precisamente es la que nos hace humanos, implica y al mismo tiempo, evitar todo lo que pueda acercar al otro a su acabamiento. En otras palabras, hacer todo por su vida, por forjar su óptimo y continuo desarrollo.

Lévinas señala la necesidad de pensar y considerar al otro, expresar sobre él y no ignorarlo, dejando de lado lo impersonal, develando la responsabilidad que se debe tener hacia el otro, puesto que todo acto le involucra y tiene repercusiones sobre él. Actuar asumiendo que se está solo y que los otros existen para recibir el producto de esas acciones es una manera de actuar con violencia hacia ellos.

Lévinas, lo plantea como la ética de la alteridad, la cual se encamina a comprender todo lo relacionado con ese otro: qué es y qué significa su rostro, qué implica la responsabilidad y la necesidad de ese ser; ya que ningún individuo está solo en el mundo, sino que como integrante de una sociedad, requiere estar en un colectivo, es decir, evitando la soledad.

Es precisamente en la no soledad, en el encuentro de sujetos, donde cobra valor la conciencia propia acerca del impacto que provocan nuestras acciones sobre el entorno social. Es ese espacio de lo público en el que se configura lo común y surge la necesidad del cuidado por el otro y por lo otro, al tiempo que se establece como escenario para lo político en el que todo acto humano se constituye en posibilidad de encuentros mediados por la palabra y la narrativa, las cuales dotan de valor social el mundo de lo común como fuente de ocupación por lo que hay fuera de sí, por lo que beneficia a la comunidad y por lo que permite que se establezcan relaciones éticas, equilibradas y justas.

Dicho de otro modo, se consolida una sociedad donde es posible el acceso de todos y todas, incluso de los niños, quienes con su pensamiento y palabra aportan a la construcción y producción de cultura en un mundo donde nadie busque dominar ni controlar, donde el otro no sea un enemigo sino 
una posibilidad de encuentro, de crecimiento y de aprendizaje. Es precisamente de las voces de los niños donde emerge la palabra, la idea, la opinión como mecanismo de participación. $\mathrm{Al}$ respecto, Langlois (2004) expresa:

La opinión no se escoge. Es algo que existe en lo más profundo de nosotros. Es la manera como reaccionamos ante lo que pasa frente a nuestros ojos, una discusión, una injusticia, una manifestación en la calle. Una opinión es un trozo de nosotros (LANGLOIS, 2004, p.24).

Así los niños no son ajenos, ellos dan su opinión como un trozo de vida, pues en la capacidad de la palabra se encuentra la riqueza de su pensar. Así, hacer referencia a la idea de lo político, como proceso que se construye en la relación con los otros, sugiere un acto de reconocimiento y escucha, un ir y venir de subjetividades y sentidos que solo se comprenden a través del diálogo y la aceptación. Sobre esta base se construye la idea de lo político, que alcanza, como diría Nussbaum, (2014), la categoría de capacidad humana, en tanto que permite a los hombres establecer acuerdos y condiciones de relación en un tejido cuya definición práctica se encuentra sustentada en la aceptación de la diversidad y la pluralidad.

\section{LA PARTICIPACIÓN DEL NIÑO, H UM A N IZACIÓN DEL HOMBRE}

"Nunca es demasiado tarde para tener una infancia feliz" Tom Robbins

La formación del niño en asuntos de la participación se convierte en un acto humano y humanizante, ya que en esta se descubre la necesidad de reflexión del ser humano sobre sí mismo y sobre su relación con los demás. Roger Hart (citado en Apud, 1993, p. 4), afirma: "participación es 
la capacidad para expresar decisiones que sean reconocidas por el entorno social y que afectan a la vida propia y/o a la vida de la comunidad en la que uno vive". Para el autor, la participación infantil le da al niño un lugar como sujeto social, pues reconoce su capacidad de actuar y expresar opiniones en asuntos que le competen directamente, en contextos como la familia, la escuela y el barrio.

Educar a los más pequeños en la participación es apostar por un proyecto humano que transforma a los sujetos de forma individual y colectiva, invita a tomar decisiones y a ejecutar propuestas que beneficien y transformen realidades; favorece la cercanía, la proximidad y el contacto con el otro, además de los procesos de escucha, de aceptación y de empatía, bajo interacciones respetuosas y afectivas; asimismo, y en tanto que reconoce la diversidad, la diferencia y la pluralidad, nos permite compartir espacios y tiempos considerando al otro como otro pero igual a nosotros. O como lo expresa Celan: "Yo soy tú cuando yo soy yo".

Este hecho hace que la participación se conciba como una de las formas de aproximación entre sujetos que se reconocen como humanos, seres únicos y diferentes, pero para quienes el otro le ofrece la oportunidad de intervenir en su propia vida y en la de los demás, asumiendo la intervención como un aspecto inherente a las relaciones intersubjetivas.

De este modo, la participación infantil se piensa como la capacidad del sujeto niño de "hacer parte de", es decir, de su compromiso al momento de reconocer y asumir sus intervenciones con responsabilidad, bajo la premisa de la escucha con respeto, la cual cobra valor y permite construir experiencias colaborativas, orientadas a la apropiación de sus deberes y derechos, enmarcado en la búsqueda de los valores colectivos.

De acuerdo con Tonucci, "Nadie puede representar a los niños, sin preocuparse de consultarlos, de implicarlos, de escucharlos" (TONUCCI, 1998, p.59); es en el trabajo 
con los niños, en la escucha con seriedad, respeto y empatía hacia y con ellos, donde se lograrán mejores formas de comunicación y participación, orientadas hacia su interés. Solo así se trazarán rutas con verdaderos aportes para la construcción de una cultura y sociedad transformadas, que permitan una renovada forma de ser y estar en el mundo.

Por ello se reconoce en el niño su carácter social, con participación activa y como una persona humana con todos sus derechos en cada etapa de la vida en la que se encuentra. Bien lo expresa Bustelo (2007): "La infancia representa la apertura del hombre y la superación de muchas tradiciones pero, sobre todo, la superación de la gramática hegemónica de un orden opresor" (BUSTELO, 2007, p. 142).

Esta idea refuerza el respeto por el derecho del niño al pleno y armónico desarrollo, la necesidad de dar valor a la forma en que forja su sistema de relaciones, orientado a poner de relieve el valor de sí mismo, de los demás y del mundo, en el que es importante que ellos cuenten con libertad de expresar, decir, decidir, opinar, querer, exigir, reclamar y contar con verdaderos espacios de ejercicio de sus derechos en los escenarios de participación social.

Resulta válido, entonces, decir que es posible educar al niño en lo político, pero también es importante decir que no es ético someterlo a responsabilidades cívicas prematuras. Aquí, las palabras de Hannah Arendt (1997) cobran un profundo valor cuando insiste en el imperioso deber del adulto de preparar al niño para el ejercicio de la vida ciudadana por medio de una educación que no lo precipite.

Podría decirse que se requiere de proyectar acciones que posean una intencionalidad, que tengan como principio promover experiencias que permitan a los niños acceder y participar del mundo que los rodea y que involucre además a todos los agentes educativos; ya que la educación y el cuidado de la primera infancia marcan la diferencia en el desarrollo de personas, y por ende, de las sociedades. Para

Educ. Foco, Juiz de Fora, 
Arendt, "en la medida en que formamos parte del mundo, la experiencia nos concede un acceso directo al mismo" (ARENDT, 1997, p.13).

Es allí, desde las acciones humanas, donde emerge la necesidad de reconocer la importancia de la infancia para la humanidad, en tanto que es el punto de partida para la emergencia de lo nuevo, de los recién llegados al mundo, como lo diría Arendt, del natalicio."La natalidad es, pues, la matriz de todas las acciones, acto de ruptura con el pasado mediante la introducción de algo nuevo en el continuom temporal de la naturaleza, en la vida cotidiana" (ARENDT, 2007, pp, 1920).

Con lo anterior, esinnegable la emergencia de la educación del niño en acciones vinculares que promuevan la relación con el otro, inclusive antes de nacer, puesto que al producirse su nacimiento ya está siendo parte de acciones que le afectan, pues se le reconoce como sersocial, ciudadano con derechos. Llega a ser parte de diversos grupos o ámbitos en los que observan, aprenden, interiorizan, analizan e inician su proceso de integración a la cultura para entablar relaciones consigo mismo, con los otros y con el entorno.

En ese transitar de su vida, el niño requiere de acompañamiento y orientación por parte de otros individuos que le posibiliten las condiciones adecuadas para adaptarse, comprender e interactuar en los entornos sociales. Este proceso educativo se inicia en la familia posteriormente, dicho proceso continúa en la escuela a través de las acciones que allí se plantean, y se espera que constituyan el fortalecimiento del ser desde una perspectiva en la que logre el desarrollo de capacidades humanas, mediante el reconocimiento de sí mismo, del otro y del entorno, en una constante relación con el conocimiento que ya posee y con el que construye, desde la más temprana edad en la que se vincula al sistema educativo.

En este sentido, Carli (1999) sostiene la necesidad

de volver la mirada sobre lo social en la escuela y priorizar en la formación de la condición humana en todos los actos educativos, especialmente en la educación infantil, teniendo 
en cuenta los cambios a los que permanentemente se enfrenta la sociedad y su impacto en la formación de los niños que hacen parte de ella, en su autoimagen y la imagen que se forman de los otros, en el autocuidado, el cuidado que manifiestan por los otros y por lo público. Es decir, es en la escuela donde se complementa esa formación iniciada en la familia y que propende por hacer de cada individuo un ser social que actúa bajo principios y valores de aceptación y respeto por sí mismo, por el otro y por lo común.

\section{REFERENCIAS}

ALVARADO, S. Ospina, H. Socialización política y configuración de subjetividades. Construcción social de los niños, niñas y jóvenes como sujetos políticos. Manizales. CINDE, 2014.

APUD, A. Siguiendo a Hart, R. Formación del profesorado Colombia. Enrédate con UNICEF. 1993 Disponívem em: $<$ http://www.sename.cl/otros/unicef.pdf $>$. Acesso em. Enero 15 de 2016

ARENDT, H. ¿Qué es la política? España: Pensamiento contemporáneo, 2007.

BUSTELO, E. El recreo de la infancia. Argumentos para otro comienzo. Buenos Aires: Siglo XXI, 1997.

CARLI, S. La infancia como construcción social. De la familia a la escuela. Infancia, socialización y subjetividad. 1999. Argentina: Santillana. Disponível em:

ht tps:// ciie-10.wikispaces.com/file/view / Carli+De+la+familia+a+la+escuela. Acesso em. Enero 15 de 2016

LANGLOIS, D, Mejía, E., Lopera, J. y Pinzón, G. La política explicada a los niños y a los demás. (p.24). Colombia: Universidad de Quindío, 2004. 
LÉVINAS, E. El tiempo del otro. Barcelona: Paidós. 1993.

Luna, M. El sujeto cuerpo. Ideas para acercarse a la comprensión del cuerpo político que somos. En Alvarado. CINDE. Socialización política y configuración de subjetividades. Construcción social de los niños, niñas y jóvenes como sujetos políticos. (pp. 133, 134) Manizales. CINDE, 2014.

NUSSBAUM, M. Emociones políticas: ¿por qué el amor es importante para la justicia? Bogotá: Editorial Planeta Colombiana S.A, 2014.

TONUCCI, F. La ciudad de los niños. Madrid: Fundación Germán Sánchez Ruipérez. 1998.

ORTEGA RUIZ, P. La educación moral como pedagogía de la alteridad. Revista Española de Pedagogía, nº 227, 2004

Data de submissão: janeiro de 2016

Data de aceite: março de 2016 